\title{
Anti-inflammatory activity of a Vernonia cinerea methanolic extract in vitro
}

\author{
Aurasorn Saraphanchotiwitthaya ${ }^{\mathrm{a}, \mathrm{b}, *}$, Pattana Sripalakit ${ }^{\mathrm{b}, \mathrm{c}}$ \\ a Department of Pharmaceutical Technology, Faculty of Pharmaceutical Sciences, Naresuan University, \\ Phitsanulok, Thailand \\ b Pharmaceutical Biotechnology Research Unit, Faculty of Pharmaceutical Sciences, Naresuan University, \\ Phitsanulok, Thailand \\ c Department of Pharmaceutical Chemistry and Pharmacognosy, Faculty of Pharmaceutical Sciences, \\ Naresuan University, Phitsanulok, Thailand
}

*Corresponding author, e-mail: aurasorns@nu.ac.th

Received 6 Aug 2014

Accepted 2 Nov 2015

\begin{abstract}
Vernonia cinerea Less. (Asteraceae) is a herbaceous plant commonly found in SE Asia. Different parts of $V$. cinerea have been used in various folklore medicine applications, including reducing inflammation and detoxification. This study investigates the effects of $V$. cinerea methanolic extract on the mouse immune system in vitro. Cytokine detection of ConA-stimulated splenocytes using ELISA, mitogen-induced splenocyte proliferation, and phagocytic activity were assayed. The results show that the extract shifted the Th1/Th2 balance towards a Th2 type response. Additionally, Th1- and Th2-related cytokine production correlated with lymphocyte proliferation by selective activation of T-cells into Th2-cells and suppression of Th1-cell proliferation. Our results confirmed the traditional applications of $V$. cinerea on immune-related remedies and anti-inflammation, suggesting a potential therapeutic application of this plant in the treatment of diseases associated with Th1-related cytokine production and inflammation.
\end{abstract}

KEYWORDS: Th1/Th2 balance, cytokine, lymphocyte proliferation, inflammation

\section{INTRODUCTION}

Cytokines are soluble glycoproteins secreted by living cells of the host, that play an important role in initiating, maintaining, and regulating immune, homoeostatic, and inflammatory processes ${ }^{1}$. Fully differentiated $\mathrm{T}$ helper (Th) lymphocytes are divided into at least two distinct subsets based on cytokine production. Th1 cells are involved in cell-mediated immunity, and produce cytokines such as interferongamma (IFN- $\gamma$ ) and interleukin-2 (IL-2). These cytokines serve to activate monocytes/macrophages, natural killer cells, and cytotoxic T cells, and are associated with host defence against bacteria, viruses, and fungi ${ }^{2}$. In contrast, Th2 cells are involved in humoural immunity and produce cytokines such as IL-4 and IL-10, which are associated with the allergic response ${ }^{3}$. The Th1/Th2 cytokine balance is believed to be important in regulating cell-mediated immunity versus allergic reactions ${ }^{2,3}$. Moreover, modulation of cytokine release by immunomodulating agents is an attractive target for treatment of several diseases such as infection, allergy, autoimmune diseases, and cancer ${ }^{4-6}$.

Recently, there has been much effort in finding a relationship between pathological processes of infection, inflammation, and cancer. Epidemiological studies have shown that approximately $15 \%$ of human deaths from cancer are linked to chronic viral or bacterial infections. Inflammatory responses play decisive roles at different stages of tumour development, including initiation, promotion, malignant conversion, invasion, and metastasis. Inflammation also affects immune surveillance and responses to therapy. Along with its pro-tumourigenic effects, inflammation also influences the host immune response to tumours and can be used for cancer immunotherapy and to increase the response to chemotherapy. In some cases, inflammation can decrease the advantageous effects of therapy. The activation of nuclear factor- $\kappa \mathrm{B}(\mathrm{NF}-\kappa \mathrm{B})$ by the inhibitor of NF- $\kappa$ B kinase- $\beta$-dependent pathway is a crucial mediator of inflammation-induced tumour growth and progression, as well as an important modulator of tumour surveillance and rejection ${ }^{7,8}$.

Plant-derived extracts have historically been 
considered to be effective in maintaining vitality, preventing and treating various diseases, and enhancing overall immune health ${ }^{9}$. Vernonia cinerea Less. (Asteraceae) is a herbaceous plant mainly distributed in tropical regions; it is commonly found in Southeast Asia, including Thailand. Different parts of $V$. cinerea have been used in folk medicine applications, and have been reported to possess medicinal properties. A mixture of $10-15 \mathrm{~g}$ of dried stems boiled in water has been used in the treatment of flatulence, diarrhoea, fever, and inflammation, while a mixture of $2-4 \mathrm{~g}$ of dried seeds in hot water has been used in the treatment of cough and chronic skin disease, and has been used to promote detoxification and general health ${ }^{10}$. $V$. cinerea possesses various pharmacological activities relating to the immunological responses such as inflammation, pain ${ }^{11,12}$, infection ${ }^{13}$, wound healing, liver disease, asthma, and bronchitis ${ }^{14}$. Thus we propose an immunomodulatory and anti-inflammatory activity of these plants. In this study, we therefore examined the effects of methanolic extracts of $V$. cinerea on the production of four Th1- and Th2-related cytokines using ELISA, and the proliferative response of mouse lymphocytes using splenocytes proliferation assays. We also evaluated phagocytic activity of macrophages/monocytes using nitroblue tetrazolium (NBT) dye reduction and cellular lysosomal enzyme activity assays.

\section{MATERIALS AND METHODS}

\section{Plant material}

Dried aerial parts of $V$. cinerea were obtained through Bang Krathum Hospital, Phitsanulok, Thailand. Plant samples were authenticated by the botanist of the Department of Pharmaceutical Chemistry and Pharmacognosy, Faculty of Pharmaceutical Sciences, Naresuan University, Phitsanulok, Thailand. An archival specimen was also prepared and deposited in the herbarium of the Faculty of Pharmaceutical Sciences, Naresuan University, Phitsanulok, Thailand.

\section{Chemicals}

3-(4,5-dimethylthiazol-2-yl)-2,5-diphenyltetrazolium bromide (MTT), NBT dye, p-nitrophenyl phosphate ( $p$-NPP), phytohaemagglutinin (PHA), concanavalin A (ConA), lipopolysaccharide (LPS), pokeweed mitogen (PWM), dimethyl sulphoxide (DMSO), phosphate buffered saline (PBS), phorbol-12-myristate-13-acetate (PMA), zymosan A, and antibiotic-antimycotic solution (100 U peni- cillin, $100 \mu \mathrm{g}$ streptomycin, and $0.25 \mu \mathrm{g} / \mathrm{ml}$ amphotericin B) were purchased from Sigma-Aldrich (St Louis, MO, USA). $\beta$-Mercaptoethanol and Triton X-100 were purchased from Fisher Scientific (Loughborough, UK). Foetal bovine serum (FBS) and RPMI-1640 media were purchased from GIBCO/BRL Invitrogen (Paisley, Scotland).

\section{Animals}

Female ICR mice (5-6 weeks old) were obtained from the National Laboratory Animal Centre, Mahidol University, Bangkok, Thailand. The animals were housed under standard conditions at $25 \pm 2{ }^{\circ} \mathrm{C}$ and were fed with standard pellets and tap water. The experiments were conducted under the surveillance of the Ethics Committee of Naresuan University, Thailand.

\section{Cell culture}

THP-1 monocytic cell lines were obtained from the American Type Culture Collection (ATCC, Manassas, VA, USA), and were cultured in complete RPMI 1640 medium (CRPMI; RPMI 1640 medium supplemented with $10 \%(\mathrm{v} / \mathrm{v})$ heat-inactivated FBS, $100 \mu \mathrm{g} / \mathrm{ml}$ streptomycin, and $100 \mathrm{U} / \mathrm{ml}$ penicillin) at $37^{\circ} \mathrm{C}$ in a humidified atmosphere containing $5 \%$ $\mathrm{CO}_{2}$. Cells were grown in suspension in $75-\mathrm{cm}^{2}$ tissue culture flasks and subcultured periodically to maintain a cellular density of $1 \times 10^{6}$ cells $/ \mathrm{ml}$. Cells were counted using a haemocytometer, and viability was assessed by trypan blue exclusion.

To induce differentiation of THP-1 monocyte cells into macrophage-like cells, THP-1 cells were cultured in the presence of $400 \mathrm{ng} / \mathrm{ml}$ PMA for $24 \mathrm{~h}$ at $37^{\circ} \mathrm{C}$ in a $5 \% \mathrm{CO}_{2}$ humidified incubator ${ }^{15}$.

\section{Extracts}

The dried materials were extracted by maceration in methanol for $24 \mathrm{~h}$ and filtered. The filtrate was evaporated under reduced pressure until the sample dried and a yield of $15 \%(\mathrm{w} / \mathrm{w}$ of dried material) was obtained. To prepare extract concentrations of $0.01,0.1,1,10$, and $100 \mu \mathrm{g} / \mathrm{ml}, V$. cinerea extract was dissolved in $0.1 \%$ DMSO in PBS solution. Insoluble material was centrifuged and the extract was sterilized by $0.2 \mu \mathrm{m}$ filtration. A solution of $0.1 \%$ DMSO in PBS was used as a control in all experiments.

\section{Mouse splenocytes}

Mice were euthanized and spleens were removed using aseptic techniques. Single cells were prepared 
by mincing spleen fragments and pressing the fragments through a stainless steel 200-mesh screen in RPMI 1640 medium. Cells were centrifuged at $1200 \mathrm{~g}$ for $10 \mathrm{~min}$ at $25^{\circ} \mathrm{C}$, washed twice and resuspended in CRPMI medium. Cell number was adjusted to $1 \times 10^{6}$ cells $/ \mathrm{ml}$, and cell viability was measured by trypan-blue dye exclusion.

\section{Mouse peritoneal macrophages}

Peritoneal macrophages were isolated following intraperitoneal injection of $\mathrm{FBS}$ as a stimulant ${ }^{16}$. Three days later, exudates were collected by peritoneal lavage with RPMI 1640 medium. The exudates were centrifuged at $1200 \mathrm{~g}$ for $10 \mathrm{~min}$ at $25^{\circ} \mathrm{C}$, and the cells were washed twice and re-suspended in CRPMI medium. Cell number was adjusted to $1 \times 10^{6}$ cells $/ \mathrm{ml}$. Cells were counted using a haemocytometer, and viability was assessed by trypan blue exclusion.

\section{Cytokine production from splenocytes}

Production of murine IFN- $\gamma$, IL-2, IL-4, and IL-10 was measured by an enzyme-linked immunosorbent assay (ELISA) according to manufacturer's instructions (eBioscience, Inc. San Diego, USA). Splenocytes were treated with extract and $5 \mu \mathrm{g} / \mathrm{ml}$ ConA for $48 \mathrm{~h}$ at $37^{\circ} \mathrm{C}$ in a $5 \% \mathrm{CO}_{2}$ humidified incubator, and the culture supernatants were analysed. Briefly, a 96-well microtitre plate was pre-coated overnight with capture antibody. After blocking and several washes, samples were incubated with working standards for $2 \mathrm{~h}$. After washes, a working detector solution containing biotinylated antimouse cytokine monoclonal antibodies conjugated with avidin-horseradish peroxidase was added to each well and incubated for $1 \mathrm{~h}$. Substrate solution was then added, and absorbance was read at $450 \mathrm{~nm}$ using a microtitre plate reader (Bio-Tek Instrument Inc., Winooski, VT, USA) within $30 \mathrm{~min}$ of the addition of stop solution.

\section{Mitogen-induced splenocyte proliferation}

Splenocyte proliferation assays were performed to detect lymphocyte proliferation as previously described ${ }^{17}$. The optimum dose $(5 \mu \mathrm{g} / \mathrm{ml})$ of mitogen (PHA, ConA, LPS, and PWM) was used to stimulate cultured cells. Briefly, splenocyte suspensions were treated with extract and mitogen for $48 \mathrm{~h}$ at $37^{\circ} \mathrm{C}$ in a $5 \% \mathrm{CO}_{2}$ humidified incubator. Subsequently, $5 \mathrm{mg} / \mathrm{ml}$ MTT was added and incubation continued for $4 \mathrm{~h}$. The culture medium was removed by aspiration, and $0.04 \mathrm{M} \mathrm{HCl}$ in isopropanol and distilled water was added. The absorbance was measured at $570 \mathrm{~nm}$ using a microplate reader. The stimulation index was calculated as mean ratio of optical density (OD) of the extract with mitogen treated cells divided by OD of mitogen treated cells.

\section{NBT dye reduction}

NBT dye reduction assays were performed as previously described ${ }^{18}$. Macrophages or THP- 1 cells $\left(1 \times 10^{5}\right.$ cells/well $)$ were treated with extract and $400 \mathrm{ng} / \mathrm{ml}$ PMA for $24 \mathrm{~h}$ at $37^{\circ} \mathrm{C}$ in a $5 \% \mathrm{CO}_{2}$ humidified incubator. Cells were incubated with $5 \times 10^{6}$ particles/well zymosan A and $1.5 \mathrm{mg} / \mathrm{ml}$ NBT dye. After incubation for $60 \mathrm{~min}$, the adherent phagocytes were rinsed vigorously with RPMI medium and washed four times with methanol. After air drying, $2 \mathrm{M} \mathrm{KOH}$ and DMSO were added, and the absorbance was measured at $570 \mathrm{~nm}$ using a microplate reader. The phagocytic index (PI) was calculated as the mean ratio of OD of the extract treated cells divided by the OD of untreated cells.

\section{Lysosomal enzyme production}

Cellular lysosomal enzyme activity was used to determine acid phosphatase levels in phagocytes as previously described ${ }^{19}$. Macrophages or THP-1 cells $\left(1 \times 10^{5}\right.$ cells/well) were treated with extract and $400 \mathrm{ng} / \mathrm{ml}$ PMA for $24 \mathrm{~h}$ at $37^{\circ} \mathrm{C}$ in a $5 \% \mathrm{CO}_{2}$ humidified incubator. The medium was removed by aspiration, and $0.1 \%$ Triton X-100, $10 \mathrm{mM}$-NPP solution and $0.1 \mathrm{M}$ citrate buffer ( $\mathrm{pH}$ 5.0) were added to each well. The cells were incubated for $30 \mathrm{~min}$, and $0.2 \mathrm{M}$ borate buffer ( $\mathrm{pH}$ 9.8) was added. Absorbance was measured at $405 \mathrm{~nm}$ using a microplate reader. The PI value was calculated as in the NBT dye reduction assay.

\section{Statistical analysis}

All experiments were performed in triplicate or quadruplicate and the results are expressed as mean \pm SD. Statistical difference (significance levels of $p<0.05$ ) between groups were assessed using a one-way ANOVA, followed by multiple comparison using Tukey's method.

\section{RESULTS}

\section{Cytokine production from splenocytes}

Secretion of IFN- $\gamma$, IL-2, IL-4, and IL-10 from mouse splenic lymphocyte cultures treated with $V$. cinerea extract was assayed using ELISA. ConA $(5 \mu \mathrm{g} / \mathrm{ml})$, a T-cell mitogen, was used to stimulate cytokine production. $V$. cinerea extract significantly inhibited the secretion of IFN- $\gamma$ in a dose-dependent fashion. 
A considerable suppressant effect of the extract was observed when administered at $0.1-10 \mu \mathrm{g} / \mathrm{ml}$; 50 and $100 \mu \mathrm{g} / \mathrm{ml}$ of extract resulted in maximum inhibition, approximately $93 \%$ less than ConAinduced secretion. The extract also inhibited the production of IL-2 and IL-4. Maximum suppression was observed at $100 \mu \mathrm{g} / \mathrm{ml}$ for IL-2 (approximately $58 \%$ less than ConA-induced secretion), and at $10-100 \mu \mathrm{g} / \mathrm{ml}$ for IL-4 (approximately $70 \%$ less than ConA-induced secretion). The extract exerted a dual effect on IL-10 production. At 0.01 and $0.1 \mu \mathrm{g} / \mathrm{ml}$, the extract significantly enhanced IL-10 secretion, and maximum enhancement was observed at $0.01 \mu \mathrm{g} / \mathrm{ml}$ (approximately $87 \%$ more than ConA-induced secretion). At higher doses, however the extract tended to reduce IL-10 secretion. These results are shown in Fig. 1.

\section{Mitogen-induced splenocyte proliferation}

The effects of $V$. cinerea extract on lymphocyte proliferation were evaluated using splenocytes proliferation assays. In the absence of mitogen, the extract did not alter splenocyte proliferation. In the presence of ConA, $0.01-1 \mu \mathrm{g} / \mathrm{ml}$ of extract caused a slight suppression of splenocyte proliferation (15\% reduction), while enhancement was observed at $100 \mu \mathrm{g} / \mathrm{ml}$ (34\% increase). When administered with PHA, however, the extract did not alter the proliferation from that of PHA alone. When administered with LPS, the extract caused a dosedependent decrease in lymphocyte proliferation; suppression was observed for extract concentrations ranging between 0.01 and $100 \mu \mathrm{g} / \mathrm{ml}$, and maximum inhibition was approximately $25 \%$ less than LPS-induced proliferation $(0.01-100 \mu \mathrm{g} / \mathrm{ml})$. When administered with PWM, the extract only affected proliferation when administered at $100 \mu \mathrm{g} / \mathrm{ml}$; this dose increased proliferation by approximately $23 \%$ compared to PWM alone. These results are shown in Fig. 2.

\section{NBT dye reduction and lysosomal enzyme production by macrophages/monocytes}

$V$. cinerea extract increased NBT dye reduction of human THP-1 cells in a non-dose dependent fashion; maximum stimulation occurred at $0.01 \mu \mathrm{g} / \mathrm{ml}$, and was approximately $30 \%$ greater than control. In contrast, $100 \mu \mathrm{g} / \mathrm{ml}$ of extract suppressed NBT dye reduction in mouse macrophages by about $20 \%$. The effect of extract on lysosomal enzyme activity in THP- 1 cells and mouse macrophages was not clearly observed.
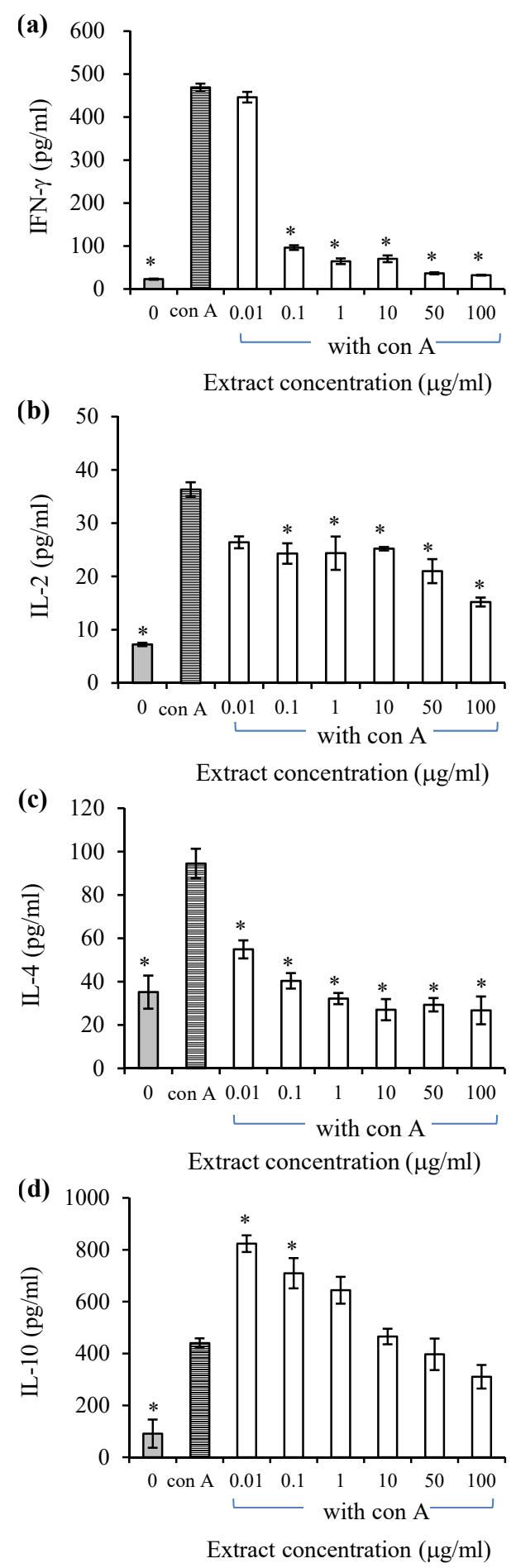

Fig. 1 Effects of $V$. cinerea methanolic extract on the production of (a) IFN- $\gamma$, (b) IL-2, (c) IL-4, and (d) IL-10 from mouse splenocytes treated with $5 \mu \mathrm{g} / \mathrm{ml}$ ConA in vitro. Each value represents the mean \pm SD of quadruplicates compared to ConA; * $p<0.05$. 


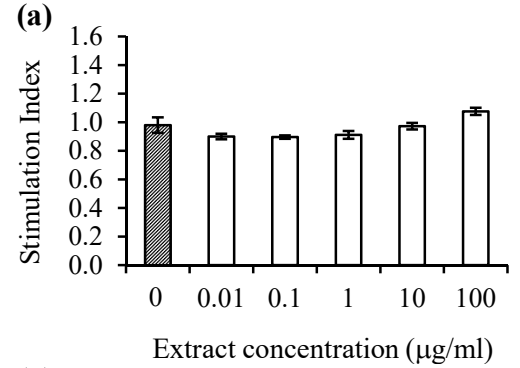

(b)

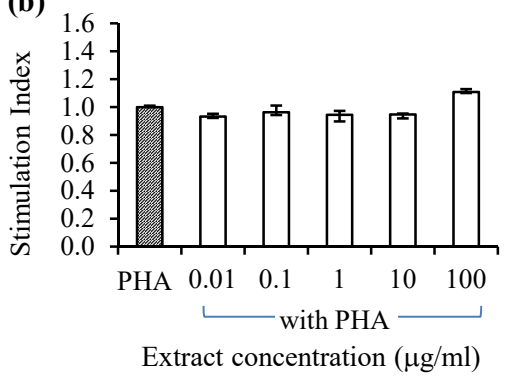

(c)
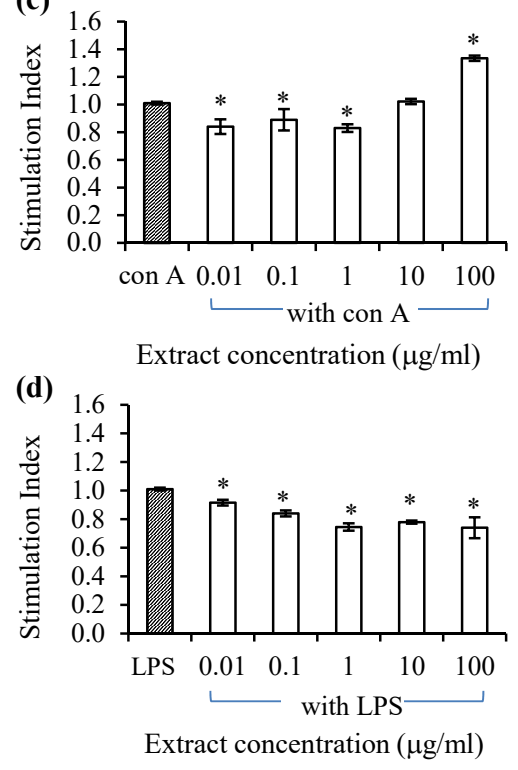

Fig. 2 Effects of $V$. cinerea methanolic extract on in vitro proliferation of mouse lymphocytes with $5 \mu \mathrm{g} / \mathrm{ml}$ mitogen: (a) without mitogen, (b) with PHA, (c) with ConA, (d) with LPS, (e) with PWM. Each value represents the mean \pm SD of triplicates compared to mitogen alone; $* p<0.05$.

\section{DISCUSSION}

In this study, the effect of $V$. cinerea methanolic extract on the production of two Th1-related cytokines (IFN- $\gamma$, IL-2) and two Th2-related cytokines (IL-4, IL-10) by ConA-activated lymphocytes was examined using ELISA. We demonstrated that $V$. cinerea extract inhibited proinflammatory IFN- $\gamma$ and IL-2 in a concentration-dependent manner. Low doses of extract promoted IL-10 secretion, while high doses tended to suppress secretion. Additionally, the extract significantly decreased IL-4 secretion. This suggested that extract-induced IL-10 secretion might contribute to the reduction of IFN- $\gamma$ and IL2 . Interestingly, the extract selectively affected Th2cytokine secretion; IL-10 was induced, but IL-4 was suppressed. These findings, together with the observed significant decrease in the IFN- $\gamma / \mathrm{IL}-10$ ratio, support the notion that $V$. cinerea extract causes Th2 polarization.

Th1/Th2 cytokine balance is one of the most important regulatory mechanisms of the immune system, and can be evaluated by examining certain lymphokine patterns that are representative of Th1 or Th2 profiles ${ }^{20}$. The observed shift of the Th1/Th2 balance towards a Th2 type response demonstrated the anti-inflammatory activity of $V$. cinerea ${ }^{21}$. The mechanisms of cytokine production might be related to gene expression, mRNA stability, or the synthesis, stability, and production of proteins, however, the exact mechanism of action required clarification.

Cytokines play an important role in regulating the proliferation and differentiation of lymphocytes $^{22}$. Hence the effect of $V$. cinerea extract on Th1- and Th2-related cytokines we observed might be partly or indirectly correlated with promoting $\mathrm{Th} 2$ fates in $\mathrm{T}$ cells while suppressing Th1 proliferation.

Lymphocyte transformation in terms of metabolic activity was augmented by $V$. cinerea extract as assessed by a colorimetric MTT assay. The mitogen used in this system may modulate possible activation pathways of the extract ${ }^{23}$. PHA and ConA were used to stimulate $\mathrm{T}$ cell activation, whereas LPS and PWM were used to stimulate $\mathrm{B}$ cell proliferation through a $\mathrm{T}$ cell-independent and a T cell-dependent pathway, respectively ${ }^{16}$. A slight suppression of ConA-induced T-lymphocyte proliferation was observed at low doses of $V$. cinerea extract, while moderate stimulation was exhibited at high doses. However, the extract did not affect $\mathrm{T}$ cell proliferation through the same mechanism as PHA. The extract together with LPS caused a dose-dependent moderate decrease in lymphocyte proliferation. In contrast, the extract was sufficient to induce proliferation when administered with PWM, but only at $100 \mu \mathrm{g} / \mathrm{ml}$. These results indicated that the effects of $V$. cinerea extract on B cell proliferation occur through T-cell independent (LPS) and T-cell dependent (PWM) pathways. Together, these observations suggested 
that $V$. cinerea extract affects both humoural- and cellular-mediated immunity.

Phagocytic activity of monocytes and macrophages was investigated using NBT dye reduction and lysosomal enzyme activity assays. Inhibition of superoxide anion production from mouse macrophages treated with $V$. cinerea extract agreed with previous studies that showed a suppressive effect of this plant on the oxidative burst of activated polymorphonuclear leukocytes ${ }^{14}$. In contrast, we observed a stimulatory activity in THP-1 cells. However, the extract did not alter acid phosphate production in either mouse macrophages or human monocytes. These results indicated that phagocytic responses may partially contribute to the anti-inflammatory activity of this plant and varied between species.

Our investigation shows that toxicity of $V$. cinerea was not a concern; more than $90 \%$ of treated ICR murine splenocytes, macrophages, and human THP-1 monocytes were viable as assayed by trypan blue dye exclusion. This was supported by the previous report which proposed that the methanol extract of $V$. cinerea did not produce toxic effects in mice or brine shrimp ${ }^{24}$. However, a sesquiterpene lactone containing in $V$. cinerea was active against HT29 colon adenocarcinoma cells and HepG2 hepatoma cells ${ }^{25}$. These suggested the selective toxicity of $V$. cinerea extract on a cancer cell line. Anti-inflammatory of sesquiterpene lactones from the flower of $V$. cinerea was reported to inhibit TNF- $\alpha$-induced NF- $\kappa$ B activity and nitric oxide inhibitory activity ${ }^{26}$. Moreover, $V$. cinerea and vernolide-A modulated cytotoxic $\mathrm{T}$ lymphocyte, natural killer cell, antibody-dependent cellular cytotoxicity, and antibody-dependent complementmediated cytotoxicity in BALB/c mice via enhanced production of cytokines IL- 2 and IFN- $\alpha{ }^{27}$. The hexane extract of $V$. cinerea did not influence cell viability of peripheral blood mononuclear cells (PBMCs), reduced proinflammatory cytokine level (IL-6) but no changes in TNF- $\alpha$ and IL-10 levels from the PBMCs ${ }^{28}$. The methanolic extract of $V$. cinerea enhanced the proliferation of splenocytes, thymocytes, and bone marrow cells both in the presence and absence of mitogens in vitro and in vivo. The extract significantly reduced the LPS induced- nitric oxide, proinflammatory cytokines in mice and enhanced the phagocytic activity of peritoneal macrophages ${ }^{29}$. The previous studies and our investigations showed immunological activity of these plants. The variations of cytokine production, splenocyte proliferation and monocytes/macrophages phagocytic activity might be due to the different cell sources, experimental conditions, harvest area and time of plant collection and preparation technique of extract.

Chemoprotective and radioprotective activity of methanolic extract of $V$. cinerea in mice were reported. Immunosuppression induced by using cyclophosphamide (CTX) or $\gamma$-rays radiation was improved by $V$. cinerea extract. The decreased levels of IFN- $\gamma$, IL-2, granulocyte monocyte-colony stimulating factor (GM-CSF) treated by CTX and IFN- $\gamma$, GM-CSF treated by radiation were increased by intraperitoneal injection of the extract ${ }^{30,31}$. Change in the levels of cytokines which was different from our results may be due to the use of conA as a stimulant on cytokine production. This observation stated that $V$. cinerea extract is a promising immunomodulator for immune balance in varied environments.

Sesquiterpenes are large and ubiquitous family of C15 isoprenoid natural products and are widely distributed in plants, microorganisms, marine organisms, and insects. These compounds have mild polarity and have low solubility in water ${ }^{32}$. The methanolic extract of $V$. cinerea is known to possess triterpenes ${ }^{33}$, sesquiterpenes ${ }^{34}$, flavonoids, and phenylpropanoids ${ }^{14}$. Immunological activities of terpenes and flavonoids found in several plants have been reported ${ }^{35-37}$. Some sesquiterpenes, especially sesquiterpenes lactones, show a wide range of biological activities, such as anti-bacterial, anti-tumour, anti-virus, cytotoxic, and immune inhibition ${ }^{32}$. The previous study reported anti-inflammatory activity of sesquiterpene lactones from the flower of $V$. cinerea by their ability to inhibit nitric oxide production and tumour necrosis factor alpha (TNF- $\alpha$ )induced NF- $\kappa \mathrm{B}$ activity ${ }^{38}$. Thus abundant amount of sesquiterpenes in $V$. cinerea might be responsible for the immunological activity we observed.

In conclusion, our results support traditional claims that $V$. cinerea possesses anti-inflammatory and immunomodulatory properties. Moreover, this investigation suggests a potential therapeutic application of $V$. cinerea extract in the treatment of diseases associated with Th1-related cytokine production and inflammation; however, careful attention must be paid to dosing. In vivo immunological assays and mechanism should also be further evaluated.

Acknowledgements: This study was supported by the National Research Council of Thailand and Naresuan University, Phitsanulok, Thailand. 


\section{REFERENCES}

1. Cutler A, Brombacher F (2005) Cytokine therapy. Ann New York Acad Sci 1056, 16-29.

2. Mosmann TR, Sad S (1996) The expanding universe of T-cell subsets: Th1, Th2 and more. Immunol Today 17, 138-46.

3. Romagnani S (2000) The role of lymphocytes in allergic disease. J Allergy Clin Immunol 105, 399-408.

4. Elenkov IJ, Chrousos GP (1999) Stress hormones, Th1/Th2 patterns, pro/anti-inflammatory cytokines and susceptibility to disease. Trends Endocrinol Metabol 10, 359-68.

5. Mu HH, Sawitzke AD, Cole BC (2000) Modulation of cytokine profiles by the mycoplasma superantigen Mycoplasma arthritidis mitogen parallels susceptibility to arthritis induced by $M$. arthritidis. Infect Immun 68, 1142-9.

6. Tzianabos AO (2000) Polysaccharides immunomodulators as therapeutic agents: structural aspects and biologic function. Clin Microbiol Rev 13, 523-33.

7. Grivennikov SI, Greten FR, Karin M (2010) Immunity, inflammation, and cancer. Cell 140, 883-99.

8. Karin M, Greten FR (2005) NF- $\kappa B$ : linking inflammation and immunity to cancer development and progression. Nat Rev Immunol 5, 749-59.

9. Spencer JW (1999) Essential issues in complementary/alternative medicine. In: Spencer JW, Jacobs JJ (eds) Complementary/Alternative Medicine: an Evidence-Based Approach, Mosby, St. Louis, pp 3-36.

10. Thiengburanathum W (1996) Thai Herbal Medicines Dictionary, Prachoomtong Publishing, Bangkok, p 819.

11. Mazumder UK, Gupta M, Manikandan L, Bhattacharya S, Haldar PK, Roy S (2003) Evaluation of anti-inflammatory activity of Vernonia cinerea Less. extract in rats. Phytomedicine 10, 185-8.

12. Iwalewa EO, Iwalewa OJ, Adeboye JO (2003) Analgesic, antipyretic, anti-inflammatory effects of methanol, chloroform and ether extracts of Vernonia cinerea less leaf. J Ethnopharmacol 86, 229-34.

13. Gupta M, Mazumder UK, Manikandan L, Haldar PK, Bhattacharya S, Kandar CC (2003) Antibacterial activity of Vernonia cinerea. Fitoterapia 74, 148-50.

14. Abeysekera AM, de Silva KTD, de Silva SRP, Sirimanne VDP, Labadie RP, van den Berg AJJ, Sluis WV (1999) Inhibition of chemiluminescence generated by zymosan-activated polymorphonuclear leucocytes by phenolic constituents of Vernonia cinerea. Fitoterapia 70, 317-9.

15. Takashiba S, Van Dyke TE, Amar S, Murayama Y, Soskolne AW, Shapira L (1999) Differentiation of monocytes to macrophages primes cells for lipopolysaccharide stimulation via accumulation of cytoplasmic nuclear factor $\kappa \mathrm{B}$. Infect Immun 67, 5573-8.

16. Manosroi A, Saraphanchotiwitthaya A, Manosroi J
(2003) Immunomodulatory activities of Clausena excavata Burm. f. wood extracts. J Ethnopharmacol 89, 155-60.

17. Mosmann T (1983) Rapid colorimetric assay for cellular growth and survival: application to proliferation and cytotoxicity assays. $J$ Immunol Meth 65 , $55-63$.

18. Rainard P (1986) A colorimetric microassay for opsonins by reduction of NBT in phagocytosing bovine polymorphs. $J$ Immunol Meth 90, 197-201.

19. Suzuki I, Tanaka H, Adachi Y, Yadomae T (1998) Rapid measurement of phagocytosis by macrophages. Chem Pharmaceut Bull 36, 4871-5.

20. Swain SL, Bradley LM, Crof M, Tonkonoggy S, Atkins G, Weinberg AD, et al (1991) Helper T-cell subset: phenotype, function and the role of lymphokines in regulating their development. Immunol Rev 123, 115-44.

21. Rachoń D, Rimoldi G, Wuttke W (2006) In vitro effects of genistein and resveratrol on the production of interferon- $\gamma$ (IFN $\gamma$ ) and interleukin-10 (IL-10) by stimulated murine splenocytes. Phytomedicine 13, 419-24.

22. Ho CY, Lau CBS, Kim CF, Leung KN, Fung KP, Tse TF, Chan HHL, Chow MSS (2004) Differential effect of Coriolus versicolor (Yunzhi) extract on cytokine production by murine lymphocytes in vitro. Int Immunopharmacol 4, 1549-57.

23. Nakamura A, Nagai K, Suzuki S, Ando K, Tamura G (1986) A novel method of screening for immunomodulating substances, establishment of an assay system and its application to culture broths of microorganisms. $J$ Antibiot 39, 1148-54.

24. Latha LY, Darah I, Jain K, Sasidharan S (2010) Toxicity study of Vernonia cinerea. Pharmaceut Biol 48, 101-4.

25. Khay M, Toeng P, Mahiou-Leddet V, Mabrouki F, Sothea K, Ollivier E, Elias R, Bun SS (2012) HPLC analysis and cytotoxic activity of Vernonia cinerea. Nat Prod Comm 7, 1259-62.

26. Youn UJ, Park E-J, Kondratyuk TP, Simmons CJ, Borris RP, Tanamatayarat P, Wongwiwatthananukit S, Toyama O, et al (2012) Anti-inflammatory sesquiterpene lactones from the flower of Vernonia cinerea. Bioorg Med Chem Lett 22, 5559-62.

27. Pratheeshkumar P, Kuttan G (2012) Modulation of cytotoxic T lymphocyte, natural killer cell, antibodydependent cellular cytotoxicity, and antibody-dependent complement-mediated cytotoxicity by Vernonia cinerea L. and vernolide-A in BALB/c mice via enhanced production of cytokines IL-2 and IFN- $\gamma$. Immunopharmacol Immunotoxicol 34, 46-55.

28. Laosim T, Chuchawankul S, Tencomnao T (2011) Immunomodulatory effect of hexane extract of Vernonia cinerea Less. trunk on human peripheral blood mononuclear cells. J Chem Pharmaceut Res 3, 188-95. 
29. Pratheeshkumar P, Kuttan G (2011) Modulation of immune response by Vernonia cinerea L. inhibits the proinflammatory cytokine profile, iNOS, and COX-2 expression in LPS-stimulated macrophages. Immunopharmacol Immunotoxicol 33, 73-83.

30. Pratheeshkumar P, Kuttan G (2010) Ameliorative action of Vernonia cinerea L. on cyclophosphamideinduced immunosuppression and oxidative stress in mice. Inflammopharmacology 18, 197-207.

31. Pratheeshkumar P, Kuttan G (2011) Protective role of Vernonia cinerea L. against gamma radiation-induced immunosupression and oxidative stress in mice. Hum Exp Toxicol 30, 1022-38.

32. Chen ZL (2010) Sesquiterpenoids. In: Xu R, Ye Y, Zhao W (eds) Introduction to Natural Products Chemistry, Science Press, Beijing, pp 81-2.

33. Misra TN, Singh RS, Srivastava R, Pandey HS (1993) A new triterpenoid from Vernonia cinerea. Planta Med 59, 458-60.

34. Jakupovic J, Banerjee S, Castro V, Bohlmann F, Schuster A, Msonthi JD, Keeley S (1986) Poskeanolide, a seco-germacranolide and other sesquiterpene lactones from Vernonia species. Phytochemistry 25, 1359-64.

35. Leu YL, Kuo SM, Hwang TS, Chiu SH (2004) The inhibition of superoxide anion generation by neutrophils from Viscum articulatum. Chem Pharmaceut Bull 52, 858-60.

36. Marquez-Martin A, De La Puerta R, Fernandez-Arche A, Ruiz-Gutierrez V, Yaqoob P (2006) Modulation of cytokine secretion by pentacyclic triterpenes from olive pomace oil in human mononuclear cells. $C y$ tokine 36, 211-7.

37. Kovačević N, Čolić M, Backović A, Došlov-Kokoruš Z (2006) Immunomodulatory effects of the methanolic extract of Epimedium alpinum in vitro. Fitoterapia 77, 561-7.

38. Youn UJ, Park EJ, Kondratyuk TP, Simmons CJ, Borris RP, Tanamatayarat P, et al (2012) Anti-inflammatory sesquiterpene lactones from the flower of Vernonia cinerea. Bioorg Med Chem Lett 22, 5559-62. 